\title{
ENFERMEDAD DE COATS DE COMIENZO EN ADULTO
}

\section{COATS DISEASE OF ADULT ONSET}

\author{
ANDONEGUI $\mathrm{J}^{1}$, ARANGUREN $\mathrm{M}^{1}$, BERÁSTEGUI L ${ }^{1}$
}

\section{RESUMEN}

Caso clínico: Se describe a un varón de 66 años que presentaba una vasculopatía retiniana exudativa que fue diagnosticada como enfermedad de Coats de aparición en adulto y fue tratada mediante fotocoagulación con láser.

Discusión: La mayor parte de los casos de enfermedad de Coats se diagnostican en la infancia. Cuando este proceso aparece en adultos el curso clínico es más benigno. Debemos considerar este diagnóstico en aquellos pacientes que presenten vasculopatías retinianas con un importante componente exudativo. El tratamiento estará indicado cuando la fovea esté amenazada por el depósito de exudados.

Palabras clave: Enfermedad de Coats, comienzo adulto, vasculopatía retiniana exudativa.

\section{ABSTRACT}

Case report: We report a 66-year-old male who exhibited an exudative retinal vasculopathy, diagnosed as Coats disease of adult onset, treated with laser photocoagulation.

Discussion: Most cases of Coats disease are diagnosed in childhood. When this entity appears in adults it usually exhibits a more benign clinical course. Diagnosis of this condition must be considered in those patients showing a retinal vasculopathy with a marked exudative component. Treatment is indicated if the fovea is threatened by lipid deposition (Arch Soc Esp Oftalmol 2008; 83: 117-120).

Key words: Coats disease, adult onset, retinal exudative vasculopathy.

ta (3). En este artículo se describe a un paciente afecto de enfermedad de Coats y diagnosticado en la séptima década de la vida.

\section{CASO CLÍNICO}

Paciente varón de 66 años sin antecedentes de interés que acude a la consulta por miodesopsias en ojo izquierdo (OI) de varios días de evolución. La

Recibido: 9/2/07. Aceptado: 28/11/07.

Servicio de Oftalmología. Hospital de Navarra. Pamplona. España.

1 Licenciado en Medicina.

Correspondencia:

José Andonegui

Servicio de Oftalmología

Hospital de Navarra

31007 Pamplona

España

E-mail: jandonen@cfnavarra.es 
agudeza visual era 0,9 en ojo derecho (OD) y 0,8 en OI. La tensión ocular era $20 \mathrm{~mm} \mathrm{Hg}$ en OD y $16 \mathrm{~mm}$ $\mathrm{Hg}$ en OI. La exploración del polo anterior era normal en ambos ojos. El fondo de ojo derecho era normal. En el fondo de ojo izquierdo presentaba exudados subretinianos masivos afectando a la retina nasal y temporal superior (figs. 1 y 2). En la retina afectada por los exudados eran visibles dilataciones irregulares de los vasos sanguineos que resultaban más evidentes en la angiografía fluoresceínica (fig. 3). Se estableció el diagnóstico de enfermedad de Coats en adulto y se realizó fotocoagulación con láser de las alteraciones vasculares de la retina temporal superior por el riesgo que presentaba la exu-

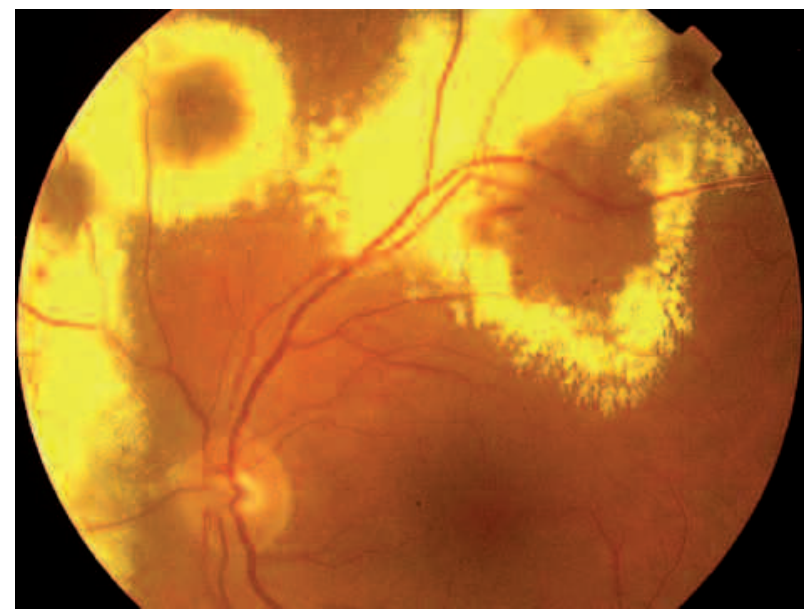

Fig. 1: Dilataciones irregulares de los vasos sanguíneos retinianos y depósito masivo de exudados duros en la arcada retiniana temporal superior y en la retina nasal.

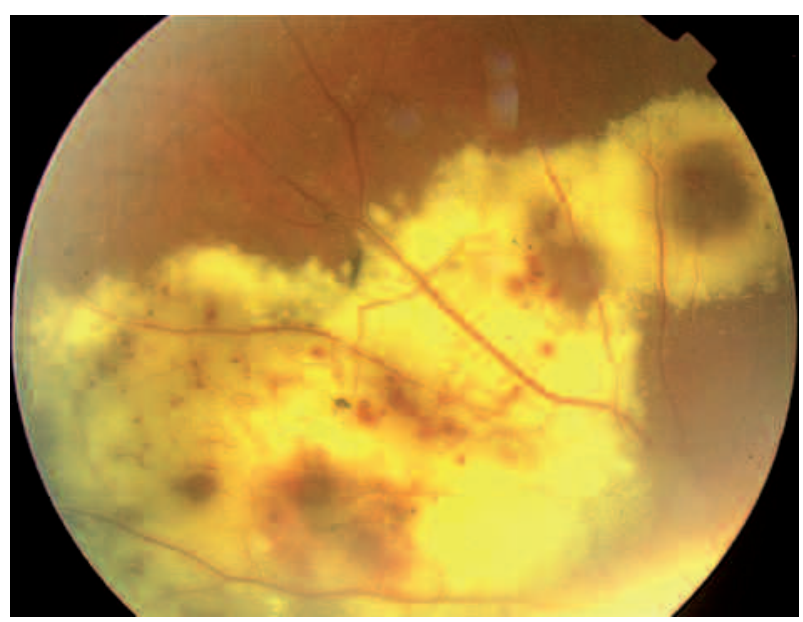

Fig. 2: Aspecto de las alteraciones vasculares y de los exudados duros en la retina nasal superior. dación en esta zona de progresión hacia la mácula. En la retina nasal se realizó fotocoagulación con láser de aquellas alteraciones vasculares que eran más fácilmente identificables oftalmoscópicamente. Seis meses después del tratamiento, el paciente conserva la misma agudeza visual y se observa una moderada disminución de los exudados duros situados en la arcada temporal superior (fig. 4). La exudación de la zona nasal apenas ha variado (5).

\section{DISCUSIÓN}

Aunque la enfermedad de Coats puede ocurrir a cualquier edad, una inmensa mayoría de los casos son diagnosticados en las dos primeras décadas de la vida. Cuando este proceso se detecta en la edad adulta, aparece también de forma unilateral y sobre todo en varones. A diferencia de lo que ocurre cuando se diagnostica en edades tempranas, muchos de estos pacientes están asintomáticos o presentan una buena agudeza visual. En estos casos, las anomalías vasculares aparecen generalmente en la retina ecuatorial y periférica y la exudación lipídica, que aparece de forma masiva y difusa en niños, se presenta de forma más localizada (3). Estos pacientes suelen mantener una buena agudeza visual y tal y como sucede en nuestro paciente la progresión de la enfermedad suele desarrollarse a un ritmo más lento. En contraste también con lo que ocurre en los niños, la enfermedad de Coats en adultos se asocia con relativa frecuencia a hemorragias retinianas provocadas por el sangrado a través de los aneurismas retinianos.

El diagnóstico de la enfermedad de Coats se establece, fundamentalmente, por el aspecto oftalmoscópico de la retina afectada. La angiografía fluoresceínica muestra hiperfluorescencia precoz de las telangiectasias, hipofluorescencia en los exudados y una leve hiperfluorescencia tardía del líquido subretiniano. También pueden aparecer zonas de no perfusión capilar o edema macular. La ecografía puede resultar útil en aquellos casos con grandes desprendimientos exudativos de la retina.

La principal entidad con la cual se debe establecer el diagnóstico diferencial de la enfermedad de Coats en los niños es el retinoblastoma (4). En los pacientes adultos debe ser diferenciada de los aneurismas miliares de Leber, siendo el principal rasgo diferencial la escasa exudación retiniana que presenta este último proceso. También, aunque de forma menos 


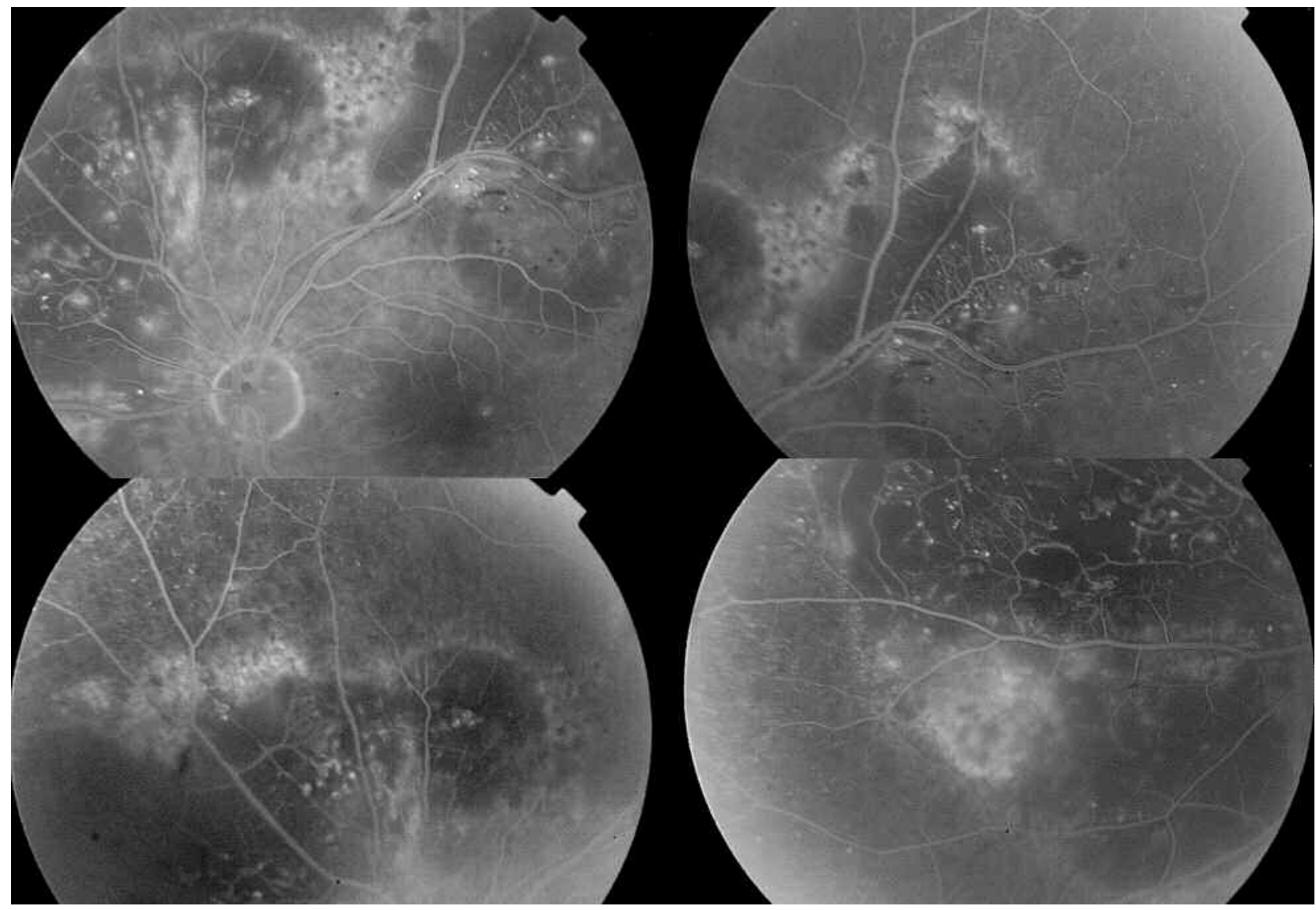

Fig. 3: Imágenes correspondientes a la angiografía fluoresceínica en las que alternan dilataciones e irregularidades de los vasos sanguíneos con zonas de bloqueo de la fluorescencia coroidea por los exudados duros.

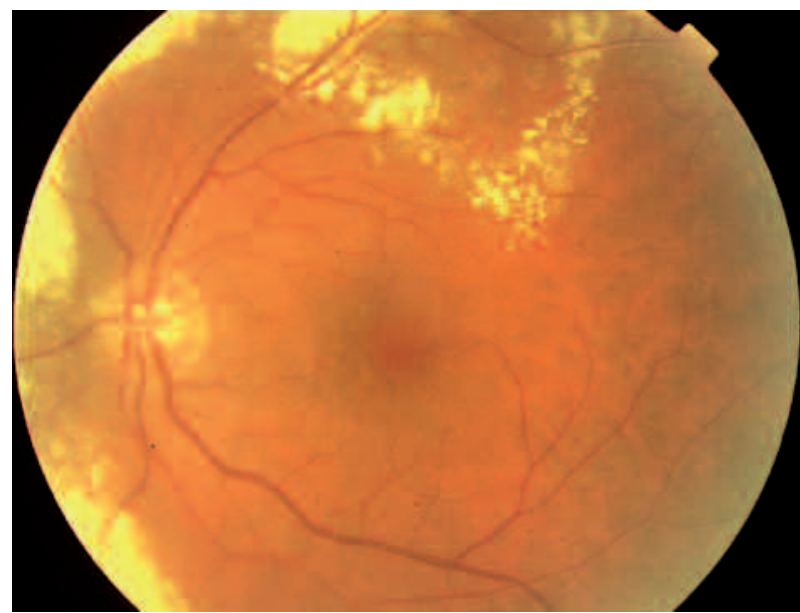

Fig. 4: Imagen del polo posterior seis meses después del tratamiento con láser en la que se observa una disminución en la densidad de los exudados duros que ocupan la arcada temporal superior.

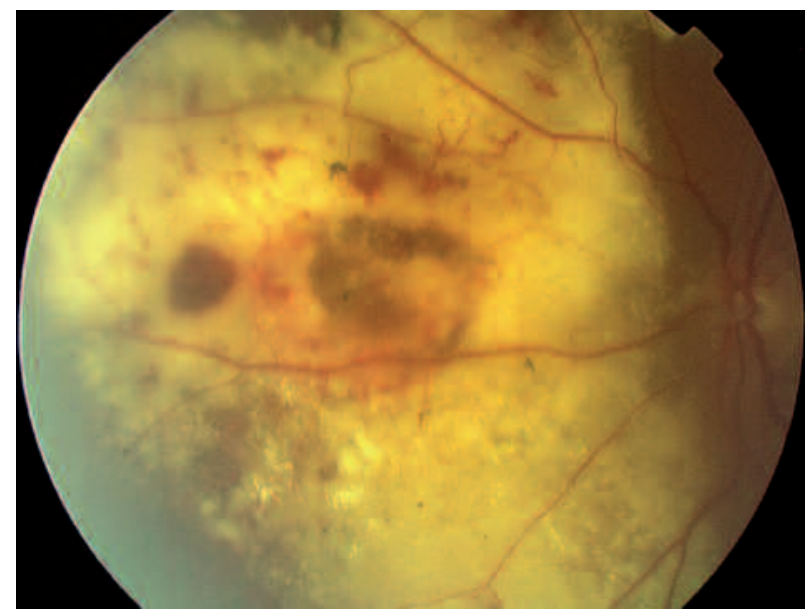

Fig. 5: Imagen de la retina nasal seis meses después del tratamiento con láser. La densidad de los exudados duros apenas ha variado. 
frecuente, puede ser confundida con un desprendimiento de retina, toxocariasis, melanoma coroideo, retinitis por citomegalovirus o toxoplasmosis (1).

En cuanto al tratamiento, su principal objetivo en esta enfermedad es obliterar las telangiectasias para promover la reabsorción de los exudados y conservar tanta visión como sea posible (2). Como posibles opciones terapéuticas se han descrito la observación, la fotocoagulación con láser, la crioterapia, el tratamiento quirúrgico del desprendimiento exudativo de retina y la enucleación. Debido a la menor agresividad que presenta esta enfermedad en pacientes adultos, el tratamiento estaría recomendado en aquellos casos en los que se demuestre progresión de las alteraciones retinianas. A pesar de que nuestro paciente presentaba una buena visón, se consideró que el riesgo de progresión de la exudación hacia la zona macular era alto y se decidió iniciar el tratamiento preventivo mediante láser.

En conclusión, aunque la mayor parte de los casos de enfermedad de Coats se presentan en la infancia, debemos considerar su diagnóstico en aquellos pacientes adultos con vasculopatías retinianas con importante componente exudativo. Aunque en estos pacientes el curso de la enfermedad es mucho más benigno y tienen un buen pronóstico en lo que a conservación de agudeza visual se refiere, valoraremos iniciar el tratamiento cuando exista riesgo de progresión de los exudados hacia la zona macular.

\section{BIBLIOGRAFÍA}

1. Shields JA, Shields CL, Honavar SG, Demirci H. Clinical variations and complications of Coats disease in 150 cases: the 2000 Sandford Gifford Memorial Lecture. Am J Ophthalmol 2001; 131: 561-571.

2. Shields JA, Shields CL, Honavar SG, Demirci H, Cater J. Clasification and management of Coats disease: the 2000 Proctor Lecture. Am J Ophthalmol 2001; 131: 572-583.

3. Smithen LM, Brown GC, Brucker AJ, Yanuzzi LA, Klais $C M$, Spaide RF. Coats' disease diagnosed in adulthood. Ophthalmology 2005; 112: 1072-1078.

4. Char DH. Coats' syndrome: long term follow up. Br J Ophthalmol 2000; 84: 37-39. 